\title{
Impactos de la entrada de China a la OMC en la maquila de confección salvadoreña
}

Claudia Carolina Hernández

Jessica Laguardia

Karen Molina

Ligia Pereira

Departamento de Economía UCA, San Salvador

RESUMEN: En el presente artículo se valoran los impactos iniciales de la entrada de China a la OMC en la maquila de confección salvadoreña. Para ello, se examinan aspectos de la regulación del sector textil y de la confección a escala mundial, junto a los antecedentes del desarrollo del rubro en El Salvador, China y Estados Unidos.

ABSTRACT: The authors assess the initial impacts that the admission of China to the WTO caused to textile maquila in El Salvador. Aspects of the regulations for textile and confection industries and its development in El Salvador, China and the United States are analyzed in this work.

\section{Antecedentes}

Para abordar el tema de los impactos iniciales de la entrada de China a la $\mathrm{OMC}$ en la maquila de confección salvadoreña, es necesario examinar aspectos de la regulación de los sectores textil y de la confección a escala 
mundial, así como indagar en los antecedentes del desarrollo de dichas industrias de El Salvador, China y Estados Unidos.

A lo largo del tiempo, los textiles y los productos de la confección han estado sujetos a diferentes regulaciones especiales a escala mundial. Entre algunos de los acuerdos que se pueden destacar estarían: el Acuerdo a Corto Plazo relativo al Comercio Internacional de Textiles de Algodón en 1961, el Acuerdo a Largo Plazo relativo al Comercio Internacional de los Textiles de Algodón de 1962 a 1973, el Acuerdo Multifibras (AMF) de 1974 a 1994 y el Acuerdo sobre los Textiles y el Vestido (ATV) de 1995 a 2005, siendo estos dos últimos, los más importantes.

El Acuerdo Multifibras (AMF), sirvió de marco para acuerdos bilaterales o medidas unilaterales de establecimiento de contingentes' en el comercio de textiles y de confecciones que establecía la posibilidad que los países importadores aplicaran restricciones cuantitativas selectivas para limitar el crecimiento de las importaciones, de textiles y confección, en caso que un rápido aumento de estas causaran o pudieran causar un daño grave a las ramas de producción nacionales. ${ }^{2}$ Luego a partir de 1995, el Acuerdo Multifibras quedó sustituido por el Acuerdo sobre los Textiles y el Vestido (ATV) de la OMC que contemplaba cuatro etapas:

- La primera etapa se inició el primero de enero de 1995, con la integración de cada miembro, de no menos del $16 \%$ del total de sus importaciones de 1990.

- La segunda etapa se inició el primero de enero de 1998, aquí se integró no menos de un $17 \%$ adicional.

- La tercera etapa se inició el primero de enero del año 2002 que integró no menos de otro $18 \%$ adicional.

- La cuarta etapa se inició el primero de enero de 2005 con la plena integración de los textiles y confección a las normas generales de comercio de la OMC y la eliminación definitiva de los contingentes. A partir de esa fecha ha quedado sin efecto el Acuerdo sobre los Textiles y el Vestido. ${ }^{3}$

Sin embargo, se estableció que los países podían tomar una serie de medidas (como la imposición de salvaguardias), si surgieran casos de perjuicio a la rama de producción nacional durante el período de transición.

A partir de enero del 2005, año en que ha expirado el ATV, los países que estaban sujetos a ese acuerdo quedan regidos por los principios 
originales establecidos por la OMC que son: ${ }^{4}$ comercio sin discriminaciones, reducción de obstáculos al comercio, comercio previsible, comercio más competitivo y comercio más ventajoso.

En lo que respecta a El Salvador, el inicio de la industria maquiladora se remonta a la época de la conformación del Mercado Común Centroamericano, por parte de los países del istmo, en este modelo, se aplicaron políticas que buscaban dinamizar la actividad textil dentro de la región centroamericana. Sin embargo, esta no funcionó por que existió un estancamiento en la aplicación de las políticas.

Posteriormente en los años setenta, el Gobierno salvadoreño en conjunto con los Estados Unidos, a través de la USAID, impulsaron las actividades maquiladoras en el país y en Centroamérica que provocaron un cambio en la estructura productiva de la región, al pasar de una industria textil a una industria manufacturera de confección dirigidas en su mayoría al mercado de los Estados Unidos. ${ }^{5}$

El desarrollo de la actividad maquiladora en El Salvador se promovió a través de la ley de Promoción de Exportaciones, que facilitó la construcción de la Zona Franca de San Bartolo en 1974. Sin embargo, el sector se vio afectado por la guerra civil en 1979 provocando el retiro del país de las empresas maquiladoras generando un estancamiento de la actividad en los años ochentas.

Durante la década de los ochentas el gobierno de Estados Unidos incentivó el comercio entre la región centroamericana y del Caribe con ese país. Para ello creó el programa llamado Iniciativa de la Cuenca del Caribe (ICC). Este programa consistía en medidas arancelarias y de comercio destinadas a promover el acceso preferencial al mercado de Estados Unidos para la gran mayoría de los productos provenientes de Centroamérica y del Caribe. A pesar de estos incentivos, quedaron excluidos productos como la mayoría de textiles y la ropa en general.

A partir de la década de los noventa, la maquila en El Salvador tuvo un relanzamiento debido a tres aspectos: la finalización del conflicto armado; un nuevo modelo económico; y un nuevo marco jurídico de ley de zonas francas. Para el año 2000, se dio una reforma a las condiciones de la ICC (2000-2008), con lo que se amplió los beneficios otorgados a los países centroamericanos y del Caribe, lo que significó un importante empuje a la industria maquilera de El Salvador. Estos beneficios permitieron un ingreso libre de aranceles y cuotas; así como también la eliminación de impuestos.

635

Impaclos de la entrado de China a la omc en la maqulla de conlecclón salvadoreña 
La maquila se ha configurado hasta la fecha, como una actividad complementaria a la industria estadounidense, con muy bajo nivel de integración nacional, que aprovecha principalmente la mano de obra barata del país, y no ha realizado inversiones importantes en modernización tecnológica. La experiencia acumulada en otros países sugiere que la concentración de la producción maquiladora en textiles y prendas de vestir limita la generación de vínculos entre las zonas francas y las empresas nacionales, lo cual resulta en bajos niveles de valor agregado local. ${ }^{6}$ No obstante, El impulso inicial que se dio en la maquila fue efímero, ya que para 2003-2004 decrecieron tanto las importaciones y exportaciones por concepto de maquila. Las primeras decrecieron en $0.1 \%{ }^{7}$ y las segundas en $2.78 \%$ en ese año. Esto puede ser atribuido a la menor demanda por parte de Estados Unidos y la creciente competencia ejercida por China. ${ }^{8}$ Por tanto, El gobierno de El Salvador ha puesto mucho empeño en las negociaciones de tratados de libre comercio, como la vía para promover las exportaciones de textiles/confección en particular y que este tipo de negociaciones puedan ser capaces de hacerle frente a los desafíos de la competencia de China.

Con respecto a China, país del este de Asia, es el tercero más grande del mundo en superficie y el mayor en cuanto a población. Su nombre oficial es el de República Popular de China; su superficie total es de $9.571 .300 \mathrm{~km}^{2}$ y más de una quinta parte de la población mundial $(1,300$ millones de habitantes) vive dentro de las fronteras de esta nación;' lo cual, lo convierte en el país más poblado del mundo, y que contrasta con los 850 millones de habitantes del continente americano desde Canadá hasta Chile, o con los 750 millones que viven en Europa. ${ }^{10}$

La economía China ha experimentado un cambio continuo y profundo desde los años setenta. Específicamente en 1979, las autoridades se trazaron como objetivo el cuadruplicar el PIB para el año 2000. Para lograrlo, se elaboraron reformas económicas que buscaban la modemización de la agricultura, la industria, el fomento de la ciencia, tecnología y la defensa nacional. Entre los elementos que incluyeron estas reformas están: una apertura económica administrada con el exterior, la desregulación de algunas actividades internas y la introducción de ciertos elementos de mercado. Sin embargo, en ese proceso de reformas, el Estado chino ha mantenido una fuerte presencia y participación en la economía." Ejemplo de ello es que se ha brindado subsidios a la producción y se han mantenido restricciones para las importaciones. 
Una de las principales estrategias de competitividad que el gobierno chino ha utilizado para atraer inversión extranjera ha sido la elaboración de paquetes de incentivos fiscales y un marco regulatorio débil en materia de derechos laborales y protección ambiental. A la vez, China posee un bajo costo de inversión inicial y mano de obra barata, llevando a esta nación a ser uno de los principales destinos de IED a nivel mundial. Los flujos de inversión extranjera han pasado de ser casi nulos en 1979 a $\$ 500,000$ millones en 2001. ${ }^{12}$

Un elemento importante es que China ha pasado de ser una economía agrícola a una economía basada en la industria manufacturera, y esto se refleja en la participación que este sector tuvo en el año 2001 en comparación al resto de sectores. En ese año, la participación de la industria en el PIB fue de $51.1 \%$ siendo la más alta de los sectores económicos ya que la participación del sector servicios fue de $33.6 \%$ y la del sector agrícola fue de $15.2 \%$. Esta nación también ha crecido dieciséis veces entre 1950 y el $2000^{13}$ pero específicamente ha crecido el doble del PIB mundial de 1980 al 2000 lo que la ha convertido paulatinamente en una gran potencia exportadora.

Esta nación se ha visto beneficiada con el enorme crecimiento del comercio mundial y más aún con su integración a la $O M C^{14}$ el 11 de diciembre de 2001; sin embargo, después de su ingreso a dicha organización, China no se ha visto exenta de conflictos comerciales importantes con otros miembros del organismo como lo es la Unión Europea (UE), que la ha acusado de hacer prácticas desleales en el comercio, vendiendo productos chinos por debajo de su costo real de fabricación. Ante tales amenazas, China y la Unión Europea han acordado que, en el período comprendido entre junio de 2005 y finales de 2007, fijarán la cantidad de exportaciones chinas a Europa en una tasa de crecimiento que oscilará entre el $8 \%$ y el $12.5 \%$ al año. ${ }^{15}$ Asimismo, China anunció que introducirá un sistema de licencias a las exportaciones de sus productos textiles con el fin de controlar el aumento de las ventas al exterior y ayudar a hacer efectivo el acuerdo logrado con la Unión Europea. ${ }^{16}$ También ha surgido una fuerte polémica entre Estados Unidos y China, relacionada al tema de textiles. La discordia surgió por las restricciones arancelarias por parte de Estados Unidos a la importación de ropa de China. La comisión estadounidense para la implementación de los acuerdos textiles está implementando restricciones arancelarias que limitarán al $7.5 \%$ el aumento anual de las importaciones provenientes de 
dicha nación asiática. ${ }^{17}$ De igual forma, otro motivo de conflicto ha sido la subvaluación del yuan (moneda china) que ha llegado a representar hasta un $40 \%$ del valor del dólar, por lo que Estados Unidos acusa a China de mantener infravalorada su moneda a "propósito" para abaratar sus exportaciones e invadir el mercado estadounidense, provocando además una fuga de puestos de trabajo al gigante asiático. China mantiene, desde 1994, su tipo de cambio casi fijo, con una ligera oscilación entre 8.2760 y 8.2800 yuanes por dólar. ${ }^{18}$

En cuanto a las características generales del mercado norteamericano de textiles y de la confección' ${ }^{19}$, hay que tener en cuenta que Estados Unidos es el principal país receptor de productos de dichos rubros provenientes de países como China y El Salvador; lo cual, se convierte en una gran competencia entre estos dos países para ganar dicho mercado.

Desde hace varias décadas, Estados Unidos ha trasladado al extranjero su producción de productos textiles y de confección debido al alto costo de la mano de obra. A partir de la década de los años cincuenta, empresas estadounidenses empezaron a trasladar sus operaciones a países como Japón, Hong-Kong, Corea del Sur y Taiwán, para llevar a cabo diferentes fases del proceso de producción. Las empresas que realizan esta deslocalización son las que elaboran ropa de marca.

A partir de 1980, la industria y el gobierno de Estados Unidos diseñaron una estrategia $(807 / 9802)^{20}$ que buscaba fortalecer su industria textil mediante el esquema de producción compartida con México y los 24 países de la ICC estos países ingresaron al mercado estadounidense al amparo del régimen (807/9802) de su sistema arancelario, lo cual, refleja la alta dependencia que dichas exportaciones tienen de los insumos estadounidenses, en particular, del uso de tela de ese país.

En el mercado de la confección de Estados Unidos participan diferentes tipos de empresas como (Walmart y Sears, entre otras) por lo general, estas no se involucran en la fabricación, sino que contratan la producción de prendas estandarizadas a fabricantes independientes en terceros países. Las Comercializadoras de marca como (Liz Clairbone, Nike y Polo) trasladaron las actividades de corte, ensamble y/o confección a países subdesarrollados, reservándose el diseño exclusivo de la prenda y la comercialización. Los productores integrados de prendas de marca trasladaron parte de sus plantas a otros países a los que les enviaron la tela y los accesorios: en un principio a los asiáticos y en la ultima década 
a México y a algunos países de Centroamérica y el Caribe, aprovechando las cláusulas del régimen 807 y otras iniciativas del gobierno de Estados Unidos.

En definitiva, desde la década de los años cincuenta hasta la fecha, las empresas estadounidenses de la industria de la confección han controlado la cadena productiva, convirtiéndose en la mayoría de los casos en fabricantes "sin fábricas". Sin embargo, hay que señalar que aún existen empresas de textiles y de hilo dentro de Estados Unidos, que son las que se oponen a la masiva invasión de productos provenientes de China, presionando al gobierno para restringir importaciones de ese país y de Centroamérica.

\section{Marco teórico}

Con el panorama anterior se ha generado una discusión acerca de los impactos iniciales que la entrada de China a la OMC esta teniendo en la industria maquiladora salvadoreña la cual tiene como trasfondo a las diferentes teorías de la competencia a nivel internacional.

La investigación se sustentó en la visión de la competencia que señala la "ventaja absoluta" en una versión moderna, la cual ha sido desarrollada por autores como Diego Guerrero."1 Esta teoría permite captar de mejor manera la dinámica de la competencia real que se da a nivel internacional, y las consecuencias de la misma. En este caso particular, ha servido para aportar elementos que explican la causa y algunos efectos que ha tenido y puede tener en un futuro el auge exportador de productos de confección de China en la maquila de confección de El Salvador.

A través de la historia de la teoría económica se han presentado varios conceptos acerca de los determinantes y de las ventajas del comercio internacional. Entre las teorías tradicionales se encuentra la teoría de las ventajas absolutas desarrollada por el economista británico Adam Smith en su libro titulado La riqueza de las naciones, en 1776. Para este autor, los países exportan aquellos bienes en cuya producción requieren menos trabajo que otro u otros países, e importan aquellos bienes en cuya producción requieren más trabajo que otra u otras naciones. La ventaja absoluta es una ventaja de costo intrasectorial ${ }^{22}$ e implica una comparación entre diversas unidades productivas del mismo bien. Además, este planteamiento toma en cuenta la teoría del valor trabajo como determinante de los precios. Esta teoría plantea fundamentalmente que el trabajo humano es la fuente del valor de las mercancías y, por lo tanto, 
los precios de los bienes están determinados por el trabajo en última instancia. Es por eso, que cada nación debe especializarse en la producción del bien que requiera de menos trabajo que la que emplea otro país y de esa manera sacar beneficio del intercambio comercial.

Diego Guerrero plantea que las ventajas absolutas deben considerarse como una ventaja de costos a nivel intraindustrial y le agrega un enfoque dinámico de la competencia.

En dicho enfoque los principales protagonistas de la competencia son las empresas que si bien pueden ser al ser incapaces de influir sobre el precio de mercado, no son en ningún momento pasivas. Al contrario, se muestran agresivas con sus rivales en busca de mayor competitividad para sobrevivir y/o ganar cuotas de mercado y/o aumentar sus ganancias. El incremento de la competitividad en el mundo real, viene dado por una mejora constante de la técnica y/o aspectos organizativos de la empresa con el fin de reducir sus costos de producción unitarios, y obtener así mayores ganancias.

El enfoque dinámico de la competencia se compone de dos tendencias que operan simultáneamente. Por un lado, a nivel intraindustrial, se forma un precio estándar para un producto homogéneo, que vendrá definido por "capitales reguladores", es decir, aquellos capitales que son los que regulan o establecen el precio de ese producto, aquellos que producen la mayor cantidad de un bien que pueden o no ser los más avanzados. Esta primera tendencia hace que en cada sector las empresas estén constantemente buscando reducir sus costos unitarios de producción para un determinado bien, y que el movimiento general de las mismas les lleve a buscar mejorar la técnica para lograrlo. Por otro lado, a escala intersectorial existen movimientos de capital ya que los inversionistas buscan dirigir sus inversiones hacia los sectores más rentables. Esta segunda tendencia, produce que se forme en la economía una tasa promedio de ganancia, es decir, que el movimiento de capital de los sectores menos rentables a los más rentables produce continuamente una tendencia hacia la igualación de la tasa de ganancia.

El enfoque dinámico señala que la característica fundamental de la competencia es que las empresas buscan reducir sus costos unitarios modificando su tecnología. Este cambio técnico se refleja en la reducción constante de los costos por unidad de producto, especialmente los costos unitarios de trabajo, dado que la tendencia en el capitalismo es a la 
aplicación de tecnología que reduzca o ahorre trabajo. Por lo tanto, una empresa que gane mercado y que tenga mayores ganancias será aquella que reduzca sus costos unitarios más rápido que las de la competencia.

El precio de costo unitario de un bien tiene una relación directa con los costos laborales (W) como los no laborales (Cc) totales, así como una relación inversa con la productividad (1/Q).Es necesario hacer las siguientes puntualizaciones:

a) Dado que las empresas al aplicar tecnología incrementan la productividad, eso dará por resultado que las cantidades físicas producidas de un bien (Q) incrementen en el tiempo. En ese caso, se espera que aunque los costos totales pudieran incrementar, los costos unitarios o medios, se reduzcan. El costo unitario pues tiene como se dijo una relación inversa con la productividad.

b) Los costos unitarios también permiten ver que la productividad es fundamental para determinarlos, sin embargo, no tiene una relación unívoca con un menor costo. Una empresa puede tener menor productividad, y a la vez podría tener un menor costo unitario. Esto teóricamente se lograría si esta consigue por alguna vía tener menores costos laborales, por ejemplo si pagara menores salarios que el resto, y/o no laborales si tuviera acceso a algún recurso no reproducible que compensen la desventaja de productividad en cantidad suficiente para tener un menor costo.

Los Costos Laborales Unitarios (CLU) pueden expresarse de la siguiente manera:

$$
\mathrm{CLU}=\mathbf{w} / \bullet
$$

En dónde:

$\mathrm{W}=\mathrm{W} / \mathrm{L}=$ Salario por trabajador

- $=\mathrm{Q} / \mathrm{L}=$ Productividad por trabajador

Dado que la aplicación de tecnología en el capitalismo incrementa la productividad, pero además esta sesgada a ser ahorradora de trabajo, cabría esperar por un lado que los costos laborales unitarios decrezcan constantemente a la par del progreso tecnológico. También es posible señalar que las empresas más avanzadas podrán tener un menor costo laboral por unidad de producto que la competencia, incluso en el caso que los salarios por trabajador sean mayores, dado que su mayor productividad les permitirá distribuir los costos laborales totales en una 
mayor cantidad de productos. La implementación de políticas para comprimir los salarios nominales y/o reales si bien puede ser un camino para reducir los costos laborales unitarios, se constituye en un elemento espurio de competencia. Esto es así, porque la reducción de los salarios encontrará eventualmente algún límite social en cada país, y por lo tanto no se podrá aplicar ilimitadamente. Además, si otras empresas consiguen mejorar constantemente su tecnología, en algún momento podrían incrementar la productividad a un nivel tal que puedan tener costos unitarios menores, aunque tuvieran salarios por trabajador mayores.

En general, los costos laborales unitarios permiten ver que es perfectamente compatible tener altos salarios y bajos costos unitarios de producción. Esto se puede lograr siempre y cuando la productividad sea lo suficientemente alta para compensar el mayor salario nominal por trabajador, y además si los costos no laborales por unidad de producto se reducen lo suficiente.

Aquel país que tenga ventajas en un sector tenderá a reducir más sus costos laborales unitarios frente al otro, y mejorará su posición comercial en esa mercancía. El país que tenga una ventaja global, experimentará una reducción relativa de sus CLU promedio, y mejorará su balanza comercial. En el caso de dos países que sean exportadores netos de un mismo bien, se puede esperar que el que experimente una reducción relativa de sus CLU en dicho bien verá incrementar su cuota de mercado exterior relativa. Cuando alguno de los países posea los capitales reguladores internacionales del sector, esa nación será la que imponga la dinámica de precios y ganancias en ese sector frente a otros países subdesarrollados y desarrollados.

En esta investigación se analizan los impactos iniciales que se han generado a raíz de la entrada de China a la OMC en la maquila de confección salvadoreña así como en algunos ámbitos económicos del país. Al ser la maquila una industria exportadora por definición, se hace necesario estudiar la participación y competencia relativa de la maquila salvadoreña y los productos textiles chinos en los mercados de destino de las exportaciones, principalmente Estados Unidos. Por lo tanto, se hace necesario hacer algunas precisiones sobre la relación del tema de estudio con el marco teórico expuesto anteriormente.

Si China tuviera una mejoría constante de sus capacidades productivas en el sector de textil y confección, que le permitiera reducir sus costos en relación a los que existen en El Salvador, esta nación lograría una reducción 
continua de sus Costos Laborales Unitarios relativos a El Salvador. Es decir, si se define los CLU relativos China-El Salvador como:

\section{CLU relativos China/ El Salvador = CLU China / CLU El Salvador (2),}

se esperaría que los CLU de China aumentaran relativo a El Salvador, es decir que el cociente de esa relación aumentaría, lo que es una ganancia de competitividad para El Salvador y una desventaja en competitividad para China. Si El Salvador desmejora su competitividad ocurriría lo contrario, y el cociente se reduciría.

En esta investigación no se ha podido obtener los CLU del sector confección para China y El Salvador. Por lo tanto, se ha hecho uso de los CLU del sector manufacturero como variable proxy del sector. En ese caso se espera al menos que si China mejora su competitividad, o se observa decrecer el cociente de los CLU relativos, eso provoque una mejora de la participación relativa de ese país en las importaciones de confección norteamericanas. Por otro lado, habría que esperar una reducción de la participación de las exportaciones maquiladoras de El Salvador hacia Estados Unidos.

Ante esta situación, las empresas salvadoreñas podrían intentar hace frente a este problema a través de dos mecanismos:

a) La disminución en los salarios para lograr reducir sus costos de producción, lo cual es una forma de alcanzar algún grado de competitividad, pero espurio.

b) A través de la implementación de nueva tecnología o nuevos procesos de producción para incrementar su productividad, reduciendo así los costos unitarios de los productos.

De persistir una tendencia de mejora de la competitividad de China, o acentuarse con el fin del acuerdo ATV, cabría esperar que tarde o temprano ese país asiático llegue a dominar el sector, debido a que contaría con una ventaja absoluta de costos más amplia. En este caso, es posible que El Salvador y otros países experimenten no sólo una desmejora relativa, sino que además una caída absoluta de sus exportaciones de confección y/o de su participación en las importaciones norteamericanas de ese rubro.

\section{El sector maquila de El Salvador}

En El Salvador, las empresas maquiladoras se han concentrado 
históricamente en actividades textiles, particularmente en la industria de la confección de ropa. De ahí se considera la maquila como sinónimo de exportaciones de confecciones textiles. Las empresas maquiladoras de confección en El Salvador, no trabajan en su mayoría bajo el esquema de paquete completo ${ }^{23}$, sino que se dedican al ensamble de piezas que provienen de las empresas que las subcontratan.

El Salvador exporta la totalidad de su producción maquilera hacia los Estados Unidos. El crecimiento de sus exportaciones lo convierte en su quinto proveedor más importante en América Latina. A nivel de la región centroamericana, El Salvador se ha convertido en el tercer exportador más grande hacia Estados Unidos, después de Guatemala y Honduras. A escala mundial se ha ubicado en el puesto número trece.

Hay que señalar, que las exportaciones brutas sobredimensionan el crecimiento real de la actividad maquiladora, debido a que esta industria importa temporalmente la gran mayoría de sus insumos - libres de aranceles- provenientes de EEUU, y, una vez ensamblado el producto, lo reexporta hacia ese país. Las exportaciones netas de maquila, en cambio, representan el valor bruto de la producción efectivamente realizada en el país, al descontarle a las exportaciones brutas de este sector, el valor de todos los insumos importados directamente por las empresas, y/o que no fueron adquiridos y/o producidos internamente. Los datos de exportaciones netas de maquila son, pues, un indicador más apegado de lo que en realidad se exporta hacia Estados Unidos.

Las exportaciones netas de confección hacia Estados Unidos muestran un crecimiento importante en la década de los noventa, si bien menores en términos absolutos a las brutas. Los datos de las exportaciones netas permiten también apreciar las altas tasas de crecimiento de la oferta exportadora del sector. Destaca que entre 1996 y 2001 pasaron de $\$ 170.06$ millones a $\$ 450.72$ millones. No obstante lo anterior, para los últimos años la variación de las exportaciones netas ha mostrado signo negativo.

Dada la importancia de las exportaciones, El Salvador otorga una serie de incentivos para la promoción y protección de las inversiones nacionales como las provenientes del extranjero. El régimen de las maquilas que posee El Salvador se encuentra normado actualmente por la Ley de Zonas Francas Industriales y de Comercialización, la cual fue publicada el 23 de septiembre de 1998. Esta ley establece dos regímenes muy similares en los que pueden operar las empresas maquiladoras. Estos son: Zona franca 
y depósito para perfeccionamiento activo o recinto fiscal. ${ }^{24}$ También existen una serie de incentivos sobre la Inversión Extranjera Directa (IED) que pretenden crear un clima de inversión en el país.

Con respecto al régimen comercial, el comercio entre Estados Unidos y El Salvador, ha estado regido por el programa llamado Iniciativa de la Cuenca del Caribe (ICC). Gracias a la ampliación que se dio en el año 2000 los productos textiles y de confección gozan de libre acceso al mercado estadounidense. El futuro régimen comercial al que estará sujeto El Salvador es el Tratado de Libre Comercio (TLC) de Estados Unidos con Centroamérica y la República Dominicana. Dicho acuerdo fue ratificado por el Congreso de los Estados Unidos el 27 de julio de 2005 con El Salvador, Guatemala y Honduras.

Por otra parte, los niveles de salarios dentro de la maquila son un elemento muy importante ya que es un sector intensivo en mano de obra, y además porque la competencia a nivel mundial es con países de salarios más bajos. La importancia de los salarios en los costos del sector es clara si se considera que la mayor parte del componente del valor agregado de la producción lo constituyen las remuneraciones de los trabajadores. ${ }^{25}$ Según estadísticas de la ASIC, El Salvador es el segundo país más caro en cuanto a costo en mano de obra a nivel centroamericano.

A nivel general, los salarios promedios nominales de la industria manufacturera se han mantenido casi estancados durante el período comprendido entre los años de 1992 y el 2003 . Es a partir de 1995, que se aplicó una política económica que ha pretendido mantener los salarios bajos para abaratar los costos salariales en el país, como vía para hacer frente a la competencia externa proveniente de la apertura comercial. Con la dolarización del país en 2001 se ha endurecido aun más esa tendencia, ya que cualquier incremento de salarios se traslada directamente en un incremento similar en moneda extranjera. Esa política restrictiva, se evidencia claramente en la ampliación a partir de 1999 del período de tiempo para ajustar y revisar el salario mínimo y los salarios públicos. ${ }^{26}$ Con respecto al salario real, se constata que a lo largo del período este ha registrado fluctuaciones que no han sobrepasado los 1,500 colones. Entre 1992 y 1993 el salario real registró su mayor crecimiento siendo este de $2.72 \%$ mientras que entre los años 2000 y 2001 tuvo su mayor caída, siendo ésta de $-6.77 \%$.

En un estudio realizado por el Ministerio de Economía ${ }^{27}$, la tasa media del sueldo por hora en la industria de la confección en El Salvador era de 
$\$ 1.58$ en $2002, \$ 1.50$ en Guatemala y Honduras, y de $\$ 2.45$ en México. Sin embargo, las tasas de sueldo en El Salvador son más elevadas que en países asiáticos donde los sueldos por hora promedian menos de $\$ 0.50 .^{28}$

\subsection{Costos Laborales Unitarios (CLU)}

Lo relevante para la competitividad de las empresas son los costos por unidad de producto. Es decir, el Costo Laboral Unitario (CLU), que relaciona los salarios y la productividad, y no tanto los salarios medios o mínimos por sí solos. Para el cálculo de los CLU, se utilizan los datos del sector de la industria manufacturera debido a que no se pudo obtener los registros pertenecientes a la maquila de confección. Sin embargo, dado que este último sector es parte fundamental de la industria manufacturera, se podría considerar que al menos la tendencia salarial podría ser similar.

En el caso de El Salvador se han observado dos períodos diferentes. Entre 1992-1998 el índice de los CLU se incrementó en 60.27\%, pasando de 100 a 160.27 lo que significa una clara desmejora de la competitividad del país en el sector manufacturero. Este aumento fue producto principalmente del crecimiento de los salarios nominales, pues éstos experimentaron un incremento del $48.95 \%$, al pasar de $₫ 1,425.79$ en 1992 a $₫ 2,123.75$ en 1998 . A su vez, en ese período, la productividad disminuyó en $7.06 \%$ pasando de un índice de 100 en 1992 a un índice de 92.94 en el año 1998. Esto indica que el crecimiento del índice de los CLU durante el período 1992-1998 se debió a incrementos en salarios y a una clara caída de la productividad.

En el período comprendido entre 1998 y 2003, los salarios nominales experimentaron un crecimiento de $6.31 \%$ pasando de $\not 2,123.75$ en 1998 a $\$ 2,257.85$ en 2003. En cuanto a la productividad, ésta se incrementó en $13.90 \%$, pasando de un índice de 92.94 en 1998 a un índice de 105.86 en 2003. Estas variaciones provocaron una disminución en el índice de CLU, ya que bajó de 160.27 a 149.60 . Esto significa que El Salvador tuvo cierta mejora en su competitividad. En este período hay que destacar que, en la caída del índice, juega un papel importante el hecho de que los salarios nominales tuvieron un crecimiento más modesto que el período anterior, y que la productividad creció casi el doble que los salarios. Esta tendencia refleja que el CLU, de la industria manufacturera ha superado el índice 100 a lo largo del período analizado, evidenciándose sobre todo la pobre evolución de la productividad sectorial. 
Los resultados del índice de los CLU, utilizando salarios reales para el mismo período muestran que la evolución a lo largo del período ha experimentado variaciones, teniendo su máximo en 1994 con un índice de 121.73 y en el año 1997 un mínimo con uno de 86.81, experimentando así una disminución de $28.69 \%$ entre esos dos años.

Entre 1992 y 1994, el índice de los CLU se incrementó en $21.73 \%$, pasando de 100 a 121.73. Esto fue producto de la disminución de la productividad, pues esta experimentó un decrecimiento de $16.32 \%$, al pasar de un índice de 100 en 1992 a uno de 83.68 en 1994. A su vez, los salarios en ese mismo período, aumentaron en $1.86 \%$ pasando de un índice de 100 en 1992 a uno de 101.86 en el año 1994. Este comportamiento de poco dinamismo de la productividad se tradujo en una desmejora de la competitividad entre 1992-1994, a pesar de la pobre dinámica de los salarios reales. En el período comprendido entre 1994 y el año 2003, los salarios reales experimentaron una disminución de $8.55 \%$ pasando de un índice de 101.86 en 1994 a uno de 93.15 en 2003. La productividad se incrementó en $26.50 \%$, pasando de un índice de 83.68 en 1994 a 105.86 en 2003 . Estas variaciones provocaron una disminución en el índice de CLU, ya que este bajó de 121.73 a 88, es decir, disminuyó en el $27.70 \%$, lo que significa que hubo cierta mejora en la competitividad, explicada por la caída de los salarios reales. Sin embargo, se puede apreciar una caída casi continua de los salarios reales desde 1993. Eso muestra que la política salarial restrictiva en el país se ha reflejado en la débil dinámica de los salarios nominales frente a la inflación, de manera de producir una caída de los reales. Ese deterioro constante de los salarios reales como se ven en los datos, ha representado un papel importante en las mejorías del índice de los CLU.

La dinámica comparativa de los CLU utilizando salarios reales y nominales indica que los CLU se reducen considerablemente más, y para un mayor número de años, cuando se utilizan los salarios reales en vez de los nominales en su estimación. Eso ofrece evidencias claras que la caída de los salarios reales se esta usando como un elemento central para competir por parte de El Salvador. Mecanismo que no está demás enfatizar que es una forma espuria y limitada de mejorar la competitividad.

\section{Importancia de la maquila en el empleo}

La actividad maquiladora en el país, especialmente la de vestuario y confección, se caracteriza por actividades intensivas en mano de obra, poco calificada dada una abundante oferta laboral de bajo costo. Según 
algunos estudios, aproximadamente el $80 \%$ de los puestos de trabajo son ocupados por mujeres jóvenes. ${ }^{29} \mathrm{La}$ actividad maquilera ha demostrado ser muy dinámica en la generación de empleos. La tasa de crecimiento promedio anual de los puestos de trabajo de maquila durante el período comprendido entre 1995 y 2004 , es de $11.6 \%$, mientras que de la PEA es de $2.7 \%$.

En la segunda mitad de la década de los noventa, se experimentó un alto crecimiento del empleo de la maquila, en donde en el año de 1997 se tuvo la mayor tasa de siendo esta de $29.3 \%$. Este crecimiento se inició a principios de la década, en lo que se denominó "el boom de la maquila". Sin embargo, en el nuevo siglo, las tasas de crecimiento han venido declinando, hasta el punto en que en el 2001 se tuvo una tasa de $-3.3 \%$. En los años siguientes, las tasas de crecimiento del empleo de maquila se han recuperado, aunque no alcanzan las tasas de crecimiento de los años noventa.

Por otro lado la maquila, según a las estadísticas del Instituto Salvadoreño del Seguro Social (ISSS), ha ido incrementando su participación en el sector industria. En 1995, el empleo en la maquila representaba $25.2 \%$ del total de empleados en el sector industria, mientras que para el año 2000 , este se elevó a $49.3 \%$, reflejando lo importante que ha sido la maquila como fuente de empleos durante los noventa.

\subsection{Importancia de la maquila en las cuentas nacionales}

Durante la década de los noventa, la maquila ha cobrado importancia dentro de la economía salvadoreña. Esta se ha convertido en el producto de exportación más importante del país. A lo largo del tiempo la maquila se ha visto caracterizado por un crecimiento constante del valor agregado, junto a tasas de crecimiento de dos dígitos para varios años y a fuertes fluctuaciones en el crecimiento.

Con respecto al PIB, se urilizó datos obtenidos del BCR en el que se muestra la importancia que tiene la industria textil y la maquila, en relación a dicho indicador. Destaca que en el período comprendido entre 19952003 la aportación de los servicios de maquila al PIB siempre ha ido en aumento. Este sector ha pasado de representar el 1.47\% del PIB en 1995 al $3.25 \%$ en el 2003 . La aportación de la maquila al PIB siempre ha superado al sector textil y al sector de prendas de vestir no maquiladoras. Los textiles no han representado más del $1.45 \%$ del PIB y las prendas de vestir no han sobrepasado el $0.5 \%$. Esto muestra la modesta contribución de la maquila al PIB. 


\subsection{Importancia de la maquila en el sector externo}

La participación de las exportaciones brutas de confección con respecto a las exportaciones totales entre los años 1999-2003, es superior al $50 \%$ del total exportado. Sin embargo, las exportaciones netas han tenido una participación menor. Estas no han sobrepasado el $16 \%$ del total exportado para el mismo período. Los datos permiten ver que, si bien la maquila es importante en el sector exportador, su aporte real como generadora de divisas es más modesto que lo reflejado por las exportaciones brutas.

Otra importancia que tienen las exportaciones netas de confección como generadoras de divisas es a través de su participación en el déficit comercial del país que se estima por el cociente de las exportaciones netas de maquila de confección sobre el déficit comercial, definiendo que las exportaciones netas de confección representaron el $11.87 \%$ del déficit comercial para 1996 y las exportaciones totales de maquila para ese mismo año representaron el $14.86 \%$. A partir de ese año hasta 1999 , la participación de ambas se incrementó reflejando $23.58 \%$ y $23.85 \%$, respectivamente. Entre los años 2000 y 2003 la participación de estas exportaciones netas y total de maquila, disminuyeron aproximadamente en $13 \%$ y $19 \%$. Lo que refleja que a partir del año 2001 , la contribución de la maquila en general ha disminuido, por lo que el déficit aumenta en la misma proporción.

\section{El sector hilo- textil- confección en China}

El país asiático ha visto crecer considerablemente su capacidad instalada en numerosos sectores manufactureros. Esto se debe a que China ha dedicado un gran esfuerzo en mejorar sus capacidades de innovación tecnológica. Por ejemplo, para mayo del año 2005, este país dedicaba a gastos en investigación y desarrollo $(\mathrm{I}+\mathrm{D})$ más del $1 \%$ de su PIB. ${ }^{30}$ Asimismo, han creado políticas que incentivan a los centros de investigación públicos a comercializar sus productos de investigación y a compartirlos con el sector privado.

Por otra parte, han sabido incrementar en pocos años su productividad en muchas industrias debido a una rápida expansión de la infraestructura física, creación de capacidades de innovación, adopción y generación de tecnologías modernas. ${ }^{31}$ Se podría considerar que China ha buscado obtener ventajas en lo que se refiere a su fuerza de trabajo abundante, barata y educada, combinado con la adopción y generación de modernos procesos tecnológicos en ciertas industrias. Por tanto, han llevado a cabo 
un proceso de integración acelerado al comercio mundial de tipo industrial, con una economía de alto conocimiento, pero que aprovecha las actividades intensivas de mano de obra y de poco contenido tecnológico para generar divisas.

El país asiático ha generado y fortalecido mucho su capacidad productiva en la cadena de hilo-textil-confección, que la ha llevado a convertirse en la actualidad en una potencia exportadora. El aumento de la capacidad instalada china se ha evidenciado en el crecimiento de las exportaciones 32 de HTC. Entre los años 1996 y 2002, las exportaciones crecieron en $\$ 54,659$ millones, es decir en $4,238.5 \%$. Destaca el hecho que el sector de confección ha determinado este crecimiento en buena medida. Por tanto, la cadena HTC, son representativas de la dinámica del sector confección.

Además, China ha adquirido muchas ventajas en el sector textil puesto que han incorporado el modelo de paquete completo (full package), avanzando así en la cadena de valor, e incorporando conocimientos y experiencias. Aunque, el país no trabaja con los diseños de la ropa ni la de la alta costura.

En cuanto a los mercados de destino, durante el período comprendido entre 1996 al 2002, las exportaciones brutas ${ }^{33}$ de China de la cadena HTC han tenido como principales mercados a Japón, Hong Kong, Estados Unidos, Corea, Australia y Alemania, en ese orden de importancia. Tan sólo en el 2002 las cantidades exportadas en este rubro a los tres primeros países fueron de $\$ 12,994, \$ 11,049$ y $\$ 5,853$ millones, respectivamente, convirtiéndose por lo tanto en sus tres principales socios en la cadena HTC. Por ello, Estados Unidos se ha posicionado claramente como el segundo mercado de destino de las exportaciones chinas de HTC, si se excluye Hong Kong, que es ahora parte de ese país. En el 2002, Hong Kong tuvo una participación del $10.6 \%$ en las exportaciones totales chinas del rubro HTC, participación que se ha incrementado considerablemente en pocos años.

Hay que destacar que China ha logrado mantener una relación de superávit creciente en su balanza comercial de la cadena HTC, con todos los países con los cuales comercia dichos productos, durante el período comprendido entre 1996 y 2002. El creciente superávit que China tiene con todas las naciones en la cadena HTC manifiesta el alto grado de competencia por parte de sus productos y muestra que muy posiblemente 
este país tiene el liderazgo global en el sector, a pesar que pueda tener desventajas en algunos productos.

China se perfila como una nación altamente competitiva a nivel mundial en la producción manufacturera, especialmente en la cadena HTC. Esto le está permitiendo a este país convertirse muy seguramente en el regulador mundial de las tendencias en los procesos de producción de la cadena HTC. Se evidencia un claro proceso por parte de China para posicionarse en los primeros lugares del sector HTC a nivel mundial, y mejorar su penetración de los principales mercados. Esto se debe en buena medida al uso de políticas económicas diversas para incrementar su capacidad instalada y competitividad en la cadena HTC.

A través de su política económica se han implementado una serie de incentivos para apoyar el desarrollo del sector HTC en general, y el de confección en particular. El gobierno de China, por ejemplo, ha subsidiado al sector textil para promover la cadena HTC, creando una base de empresas nacionales y extranjeras. Hay que mencionar que cerca de la mitad de la industria textil china es de propiedad estatal. El subsidio se ha dado mediante préstamos de bancos estatales a las mismas fábricas de propiedad del estado, y en la mayoría de los casos los préstamos no son reintegrados. Además, las cargas sociales a cargo del empresario chino, como seguros y aportaciones a la seguridad social son prácticamente inexistentes.

En el ámbito fiscal, las empresas exportadoras reciben un trato más favorable, puesto que pagan un IVA reducido del $13 \%$, frente al tipo general del $17 \% .^{3+}$ Desde la óptica económica empresarial, se han consagrado como prácticas habituales el reembolso de $30 \%$ de los costos de las primas de seguro para la exportación, así como el $30 \%$ de los gastos para la certificación de la calidad.

En lo que se refiere a costos, China ofrece las menores tasas promedios de impuesto corporativo sobre ingresos, la menor variación del tipo de cambio, una contribución patronal a costos de seguridad de 0 en relación al PIB y el menor costo de electricidad para clientes industriales en relación a países como Malasia, México y Estados Unidos, atrayendo así mayor IED.

En el caso de los costos salariales, China es un país que se caracteriza por tener costos salariales bajos en el sector de confección, por lo que esta nación al ser comparada con los países de la región centroamericana resulta ser más barata. Como se puede ver en el cuadro 12, China posee 
un salario mínimo en dólares por día más bajo respecto a todos los países de la región centroamericana, siendo este de $\$ 2.01$. Este dato muestra una ventaja en cuanto al costo por unidad de trabajador que tiene el país asiático frente a países centroamericanos que compiten en maquila, que seguramente es un atractivo para recibir pedidos de empresas extranjeras de marcas.

Cuadro 1

\begin{tabular}{|c|c|}
\hline \multicolumn{2}{|c|}{ Salarios mínimos en la maquila de confección } \\
\hline País & $\begin{array}{c}\text { Salarios mínimos } \\
\text { vigentes } 2003 \text { \$/día }\end{array}$ \\
\hline Costa Rica & 11.39 \\
\hline El Salvador & 5.16 \\
\hline Guatemala & 4.31 \\
\hline Honduras & 4.06 \\
\hline Nicaragua & 2.26 \\
\hline China* & 2.01 \\
\hline
\end{tabular}

Fuente: ASIC. "Perfil de la industria confección textil salvadoreña", 2003. p. 97

El cálculo de los CLU en China para analizar la evolución de la competitividad, se ha realizado para el sector manufactura al igual que en El Salvador. Esto quiere decir que los CLU de la manufactura se han tomado como representativos de la tendencia de la cadena HTC y particularmente la del sector de confección.

A lo largo del período 1992-2003 los salarios nominales en la industria manufacturera de China, se han incrementado en $415.27 \%$. A su vez, la productividad laboral ha registrado un crecimiento continuo, siendo este de $379.42 \%$ durante el mismo período.

Durante 1992-2003, el índice de los CLU han oscilado entre un valor mínimo de 96.92 y uno máximo de 113.34. Los datos muestran que si bien los CLU crecen, en general no se han alejado más del 10\% del valor que tuvieron el año base de 1992. Esto se explica por el hecho que la productividad laboral en general ha compensado en gran medida el incremento de los salarios promedio nominales de la manufactura. Esto mostraría que China ha logrado mantener sus CLU casi constantes debido, 
principalmente, a incrementos de la productividad, que han sido suficientes para compensar sus salarios crecientes.

Estos resultados de la industria manufacturera, al ser una proxy de la tendencia que sigue la cadena HTC y en específico el sector de confección, dan evidencias que la competitividad China si bien puede provenir de un nivel inicial de salarios más bajos, tiene también entre sus explicaciones un claro esfuerzo de ese país por incrementar su productividad laboral que incluso le permite compensar algún crecimiento salarial.

En el caso de los CLU, utilizando los salarios reales, se puede analizar la productividad, los salarios e inflación. Se constató la tendencia de crecimiento de los salarios reales pero además el crecimiento de la productividad. Los salarios han experimentado un crecimiento de $441 \%$ entre $1992-2003$ y la productividad laboral, uno de $379.42 \%$.

China inicia los noventa con incrementos en su productividad mayores que el incremento de los salarios, lo que lleva a que el índice de los CLU decrezca y muestre un valor menor al del año base de 1992. Sin embargo, en 1999 el crecimiento del índice de salarios empieza a aproximarse al de la productividad laboral, lo que lleva a que los CLU crezcan ese año por encima del nivel que tuvieron en 1992. A partir del año 2001, el crecimiento del índice salarial sobrepasa al de productividad, elevando de esta manera los costos laborales unitarios por arriba de 1992. Sin embargo, hay que señalar que entre 2001 y 2003 el crecimiento de los CLU nunca ha sobrepasado el $15 \%$ respecto al año base de 1992 , y con crecimientos anuales muy pequeños.

Los datos señalan que para el período de 1992-1998, China ha sabido mejorar o mantener su competitividad general, medida por sus CLU, sobre todo debido a incrementos de su productividad. Ese crecimiento de productividad ha sido de tal magnitud, que le ha permitido incluso reducir sus CLU a pesar de tener importantes incrementos de los salarios reales. Para el período de 1999-2003 hay una leve desmejora de la competitividad del país, debido al crecimiento de los CLU, por un alza salarial mayor que la productividad. Destaca sin embargo, que para el período 2001-2003 se mantiene un crecimiento muy alto de la productividad, que no obstante es menor que el crecimiento salarial.

Al comparar ambos índices, se puede evidenciar que China ha sabido mantener $y / o$ mejorar su competitividad en general, producto principalmente de crecimientos en su productividad, en un contexto de 
incremento de los salarios nominales y reales. Si bien el país asiático pueda tener salarios menores en muchas ramas, un elemento central para mantener o ganar competitividad en la manufactura es el incremento de la productividad, en un contexto de cierto crecimiento de los salarios nominales y reales.

China ha logrado adquirir en pocos años una gran capacidad instalada de alta tecnología, que les permite disfrutar de una alta productividad a bajos costos, especialmente en el segmento de confección, ya que constituye su principal componente de exportación de la cadena HTC. Además este país muestra una dinámica importante de mejoramiento de la productividad en el sector manufacturero, en un contexto de crecimiento de salarios nominales y reales, que le permite mantener más o menos estables sus CLU nominales y reales.

En cuanto a la importancia económica del sector HTC, esta se ha ido incrementando a lo largo del período 1996 y 2002. Tanto el PIB en la industria manufacturera, como las exportaciones totales de la cadena HTC en esta nación, se han visto incrementadas, mostrando un constante crecimiento económico.

La participación global de las exportaciones de la cadena HTC en el PIB de manufactura es de $5.42 \%$ durante el total del período. Se puede constatar que la economía china ha ido incrementando su dependencia de este sector, ya que este representa una parte del total producido en la manufactura de ese país. Además, China posee aun porencial y capacidad de crecimiento en el sector HTC, sin necesidad de generar una dependencia muy grande en el mismo.

En lo que respecta las exportaciones totales de China, el sector de la cadena HTC ha incrementado su participación en dicho rubro, mostrando la creciente importancia como generador de divisas. La participación de las exportaciones chinas de HTC en el total de sus exportaciones pasó de ser muy bajo a mediados de los noventa, a tener un fuerte crecimiento a finales de esa década. Por ejemplo, las exportaciones HTC chinas representaron un $15.55 \%$ del total exportado por ese país en 1999 , cuando tan sólo un año antes habían representado $7.59 \%$. A inicios del nuevo siglo, el peso de las exportaciones de la cadena HTC es de un promedio de $16.6 \%$, por lo que las exportaciones de la cadena HTC cobran importancia año con año, resultado de los incrementos en su productividad y prácticas agresivas en el comercio internacional. 
La balanza comercial de China en los últimos años ha resultado ser superavitaria en casi toda la década de los noventa e inicios del siglo XXI. En el 2002, este país gozaba de un superávit de \$22,600 millones. En 1998 experimentó el mayor superávit de $\$ 43,470$ millones, época en la cual China iniciaba su auge exportador dentro de la economía internacional.

A lo largo del período analizado, tanto la balanza comercial de la cadena HTC como la balanza total han registrado superávit. Por lo que se constata la importancia que ha tenido este sector en la contribución del superávit total. Se demuestra que la contribución de la cadena HTC ha aumentado año con año, incluso llegando a contribuir en más del $100 \%$ en el superávit total, pasando de $4.07 \%$ en 1996 a $194.50 \%$ en el año 2001.

Por tanto, las actividades de confección de China, visto a través de la cadena HTC, han mostrado un considerable crecimiento durante la década de los noventa, consolidándose como un sector exportador neto y mostrando una creciente importancia económica.

5. Análisis comparativo de la dinámica de la maquila de confección de El Salvador y la cadena HTC de China: Impactos en El Salvador

Para el análisis comparativo de las exportaciones de El Salvador y China, se hace necesario observar la evolución que han tenido las exportaciones de estos países hacia el mercado de Estados Unidos, también hay que señalar que podrían compararse las exportaciones brutas de maquila de confección salvadoreña con las brutas de China. Sin embargo, el uso de exportaciones brutas en la maquila salvadoreña sobredimensiona las exportaciones reales del país en el rubro, y por lo que la comparación se volvería más difusa de la desmejora del país respecto a China.

En el caso de las exportaciones de El Salvador estas eran mayores que las chinas en $\$ 196.11$ millones en el año de 1997, pero a partir de 1998 que China supera las exportaciones salvadoreñas. Pero es el año 2003, cuando el sector confección de China experimentó uno de sus mayores crecimientos absolutos, ya que sus exportaciones hacia Estados Unidos crecieron en más del doble. Ese crecimiento espectacular del 2003 se reflejó en que las exportaciones chinas superaron a las salvadoreñas en $\$ 6,917.1$ millones en el año 2003, cuando en el 2002 la diferencia era de \$ 3,542 millones. Es decir, las exportaciones de confección chinas han tenido un gran despegue a partir del 2001 , pues pasó de crecer en $1.06 \%$ en el 
año 2001 a $84.49 \%$ en el año 2003. En cambio, El Salvador experimentó no sólo una fuerte reducción en sus tasas de crecimiento respecto a los períodos previos, sino que incluso a partir de 2002 ha tenido tasas negativas. Los datos reflejan la fuerza que tiene China frente al resto de naciones, pues ha podido superar a competidores más cercanos como Centroamérica, y en particular a El Salvador, en pocos años.

Un indicador de la cuota del mercado norteamericano que tiene cada país puede ser las exportaciones de confección de cada nación sobre el total de importaciones de confección de Estados Unidos. Las exportaciones netas de la maquila de confección de El Salvador han representado entre un $0.49 \%$ y $0.8 \%$ de las importaciones de confección totales norteamericanas en el período 1997-2003. En el caso de China este indicador ha fluctuado entre el $0.22 \%$ y el $11.87 \%$. Para el año de 1997 la cuota china representaba el $0.32 \%$ de la de El Salvador, pero en el año 2003 ésta ha llegado a ser de $21.29 \%$. Estos datos reflejan que Estados Unidos no sólo ha importado mayor cantidad de productos de confección de China, sino que además indican que El Salvador pierde importancia relativa respecto a China. Este dinamismo de crecimiento de la cuota china esta posiblemente muy relacionado al ingreso de China a la OMC $\mathrm{y}$ al incremento de las cuotas que contemplaba el ATV. En el período previo al ingreso de China a la OMC, esta nación tuvo una cuota de mercado promedio de 5.26 veces la de El Salvador, y en el período posterior a su ingreso (2001-2003) su cuota ha sido en promedio 13.06 veces la de El Salvador. Esto refleja que China ha mejorado considerablemente su posicionamiento en el mercado norteamericano relarivo a El Salvador desde 1997, pero la tendencia más acentuada ha sido a partir del 2001.

En resumen se puede decir, en primer lugar, que los daros de la mejora acelerada de China a partir de 1997 pueden ser un indicador de sus esfuerzos por desarrollar su industria de confección. En segundo lugar, la acentuación del mejoramiento chino a partir del 2001 puede ser un indicador de los efectos positivos que le ha representado su entrada a la OMC, y además del aumento de cuotas que contemplaba el ATV. Y en tercer lugar, los datos del desmejoramiento absoluto, relativo y de la cuota comparativa de El Salvador a partir del 2001 pueden ser evidencias iniciales de la afectación negativa que ha traído el auge chino para El Salvador. 
Otro elemento que permite ver la mejoría que ha tenido China en cuanto a su posicionamiento en el mercado norteamericano es a través de los CLU. Es por ello, que se hace necesario realizar un análisis de la competitividad relativa de los dos países. Como se señaló en el marco teórico, esta investigación esta sustentada en la visión de la competencia que señala la "ventaja absoluta". Esta teoría incluye el análisis de los CLU, por ser considerada una variable que refleja la evolución de los costos de producción de los bienes comercializables entre países, y en ese sentido un indicador de la mejora o desmejora de competitividad.

Es importante recordar que según Diego Guerrero ${ }^{35}$, para la teoría de la ventaja absoluta lo relevante es analizar entre dos o más países cuál tiene el menor costo unitario intrasectorial, es decir en un sector productivo, el que tenga el menor será el que tenga ventaja absoluta sectorial. La evolución en el tiempo de esos costos, por otro lado, dirán si un país mejora o desmejora su situación inicial. Hay que aclarar que en el trabajo nos se adopta una comparación de los niveles absolutos de CLU, dada la dificultad para hacer comparaciones en una moneda internacional, sino que más bien se hace un análisis de la evolución de los mismos.

Por lo consiguiente, se hace un análisis comparativo de la evolución de los CLU relativos de la manufactura ${ }^{36}$ para obtener cual de los dos países esta mejorando su competitividad global. Por lo tanto un crecimiento de los CLU relativos, definidos de esa manera, señala una mejora de competitividad de El Salvador con respecto a China y su decrecimiento una desmejora de la misma. Para lograr dicho objetivo se han estimado tres diferentes costos unitarios de trabajo utilizando diferentes tipos de salarios: salarios nominales en moneda local, salarios reales en moneda local y salarios nominales en dólares.

En el siguiente gráfico se muestra la evolución de la competitividad que tiene El Salvador con respecto a China utilizando los diferentes CLU, calculados a partir de los tres diferentes tipos de salarios mencionados. 


\section{Gráfico 1}

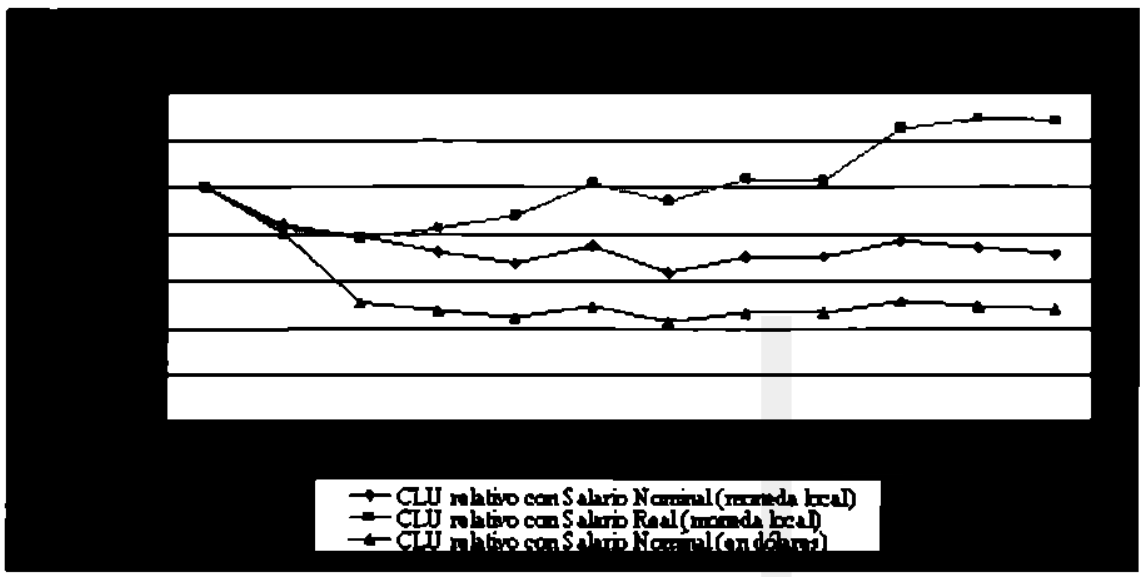

Fuente: Elaboración propia, en base a datos de la cesis de graduación de Manuel Delgado y Margarita Parada, Determinantes estructurales del salario y salarios de eficiencia: modelo de nutrición de El Salvador y de Observatorio de Coyuntura Económica. Universidad de Valencia.

A partir del gráfico anterior se destaca que El Salvador mejora su situación respecto a 1992 utilizando los salarios reales, pues el índice crece en general, y la desmejora al considerar salarios nominales en moneda local y en dólares, pues el índice decrece en general.

Tomando en cuenta los resultados diferenciados de los tres tipos de CLU, a continuación se procede a analizar, en un primer momento, la evolución de los CLU relarivos con salarios en dólares y salarios nominales en moneda local; $y$ posteriormente, la tendencia de los CLU relativos con salarios reales.

a) CLU relativos con salario nominal en dólares y en moneda local

En el gráfico 1, se observó que los CLU relativos nominales en moneda local y en dólares tienen una tendencia similar que indica una mejora de competitividad para China. Es necesario hacer una consideración previa sobre los CLU relativos estimados a partir de salarios en cada moneda. La consideración es que los CLU relativos utilizando salarios en una divisa extranjera puede ser más relevante para analizar la evolución de la competitividad de dos o más países, que cuando se ocupan los nominales o incluso reales en moneda local. La razón fundamental es que por lo general los países realizan su comercio internacional en una divisa externa, 
en este caso como se sabe el dólar es la moneda predominante, y por lo tanto el costo en esa moneda será lo relevante al momento de analizar las ventajas o desventajas comparativas de industrias de países.

En este apartado se inicia el análisis con los CLU en dólares considerando que pueden ser más relevantes que los nominales en moneda local y los reales para analizar la tendencia de la evolución de la competitividad.

En la investigación se evidenció claramente la caída del CLU relativo China/El Salvador lo que muestra una desmejora de la competitividad de El Salvador respecto a China, tomando como punto de referencia el año base de 1992. Si se toma el índice de los CLU relativos se pudo apreciar que, a pesar de altibajos en algunos años, nunca recupera el valor de 1992. El hecho que el índice se mantenga disminuyendo respecto a 1992, es decir sea menor que 100 para todos los años, indica que los CLU de El Salvador han crecido respecto a los de China durante el período 19922003. Esto se puede interpretar recíprocamente como que en ese período los CLU de China han disminuido respecto a los de El Salvador, tomando como punto de referencia el año de 1992. En cualquier caso, el CLU muestra una mejora de la competitividad del país asiático con respecto a El Salvador.

Hay que señalar que a partir del año 2001 hasta el año 2003, se evidencia que la tasa de crecimiento de los CLU relativos reflejan una desmejora anual de la competitividad de El Salvador, ya que registró tasas de crecimiento negativas de $3.83 \%$ y $3.33 \%$ para el año 2002 y 2003 . Por lo tanto el CLU relativo indica que El Salvador desmejora su competitividad respecto a China en los últimos dos años.

Para analizar que papel juegan la evolución de los salarios y la productividad de China respecto a El Salvador en la tendencia de los CLU arriba descrita, hay que recordar que los Costos Laborales Unitarios para un país se definen como $C L U=w / \bullet$, lo que quiere decir que se relacionan directamente con los salarios medios (w) e inversamente con la productividad $(\bullet)$. Con los CLU relativos, la relación es similar sólo que en este caso los salarios y la productividad son relativos China/El Salvador. Esto quiere decir que los CLU relativos en dólares tendrán una relación directa con el índice de salarios China/El Salvador y una inversa con la productividad China/El Salvador, tal como lo demuestra la expresión siguiente: 


$$
\mathrm{CLU} c b / e s=(\mathrm{W} c b / \mathrm{W} e s) /(\bullet c b / \bullet e s)
$$

En donde:

(W $c h /$ W es) es el cociente del índice de salarios China/El Salvador

$(\bullet c h / \bullet e s)$ es el cociente entre la productividad de China/El Salvador

$\mathrm{Al}$ analizar los índices relativos de salarios en dólares, se constató que las remuneraciones crecieron en mayor proporción en el país asiático respecto a los salvadoreños, ya que a partir del año base (1992) hasta el año 2003 , el índice de salarios relativos aumentó en $116.78 \%$. En cuanto a los índices de productividad relativa, se constata que para el mismo período, estos han aumentado año con año, llegando a tener un crecimiento en el 2003 de $352.88 \%$ respecto a 1992 , lo que indica que la productividad en China ha crecido en mayor proporción que en El Salvador. Los datos muestran que el crecimiento mayor de los salarios de China respecto a los de El Salvador entre 1992-2003, ha sido compensado por los incrementos de la productividad asiática mayores que los salvadoreños, lo que ha hecho que siempre disminuyan los CLU relativos China/El Salvador. Esto evidencia que mejoras en la competitividad relativa de un país son compatibles con crecimientos de salarios mayores que otro país, a través de incrementos en la productividad mayores, tal como los datos muestran que ha hecho China.

Por otro lado, al calcular los CLU relativos con salarios nominales en moneda local se observó que la competitividad de El Salvador con respecto a China también ha desmejorado. Sin embargo, hay que señalar que la mejoría estimada con los CLU relativos nominales es menor que la señalada por los costos laborales en dólares. Esto es consecuencia de los movimientos experimentados por los índices de salarios al introducir el tipo de cambio, ya que la productividad es la misma en ambos CLU. Entre el año base de 1992 y el año 2003, el índice de salarios nominales en moneda local se incrementó en $225.38 \%$, mientras que en dólares fue de $116.78 \%$. Lo anterior indica dos cosas:

a) Los salarios nominales relativos en moneda local, al igual que su equivalente en dólares, muestran que las remuneraciones chinas crecieron en mayor medida que las salvadoreñas durante el período 1992-2003.

b) China tiene una política cambiaria más flexible que le permite reducir en alguna medida la tasa de crecimiento de sus salarios, cuando se expresan en una moneda extranjera respecto a la tasa de los salarios en moneda local. 
En general, se puede apreciar que lo que se refleja a través de la mayor reducción de los CLU relarivos China/El Salvador en dólares respecto a sus similares en moneda local, es que las devaluaciones chinas han permitido que si bien el índice de salarios en dólares relativo China/El Salvador crezca, este tenga un menor ritmo de crecimiento que su similar en moneda local. Estos datos permiten ver que la política cambiaria de devaluaciones ha estado jugando un papel activo en las mejoras de la competitividad china. Es decir, que el mejoramiento de su competitividad también se le puede atribuir a la capacidad que este país tiene de hacer fluctuar a su conveniencia el tipo de cambio, ya que mantiene desde 1994 una ligera banda de oscilación entre 8.2760 y 8.2800 yuanes por dólar. Al ser este tipo de cambio fluctuante, China puede usarlo a su conveniencia para así, abaratar sus exportaciones y mejorar su posicionamiento en mercados externos, especialmente en el estadounidense. El Salvador por el contrario no o puede realizar por tener atado su tipo de cambio a una paridad fija al dólar ( 8.75 colones por un dólar), a raíz del proceso de dolarización.

\section{b) CLU relativos con salarios reales}

Los CLU reales en moneda local se podría decir que son un indicador que permiten medir mejor el papel que juega la política salarial interior dentro de la competitividad de los países. También hay que considerar que los CLU reales en moneda local son los que permiten ver si efectivamente los salarios han crecido, pues se elimina a los nominales el efecto del incremento de los precios que ocurre en moneda local.

Como se mostró en el gráfico 1, los Costos Laborales Unitarios China/ El Salvador ofrecían datos en el sentido de una mejoría para El Salvador en relación a China, a diferencia de los CLU relativos nominales y en dólares que señalaban lo contrario

Se pudo apreciar que la tendencia del índice de los CLU reales China/ El Salvador, a partir de 1997 es al alza, superando a partir de este el nivel que tenía en el año base de 1992. Esto significa aparentemente una mejora de competitividad para El Salvador y una desmejora para China. Esta mejoría debe responder a un comportamiento diferenciado del índice de salarios reales China/El Salvador respecto al similar de salarios nominales, dado que la productividad es la misma que los dos CLU analizados con anterioridad.

Se constató que el índice de salarios reales China/El Salvador ha crecido durante el período de análisis, lo que muestra que las remuneraciones del 
país asiático han crecido en mayor proporción que en El Salvador. Un hecho importante a mencionar es que mientras las remuneraciones reales de China han crecido considerablemente durante el período 1992-2003, en El Salvador estos han permanecido casi estancados, $e$ incluso han tenido caídas para no pocos años.

Los salarios reales de China entre el año base 1992 y 2003 experimentaron un crecimiento de $440.7 \%$, mientras que los de El Salvador se redujeron en $-6.84 \%$. Estas cifras muestran pues que en China las remuneraciones reales crecen mientras que en El Salvador han decrecido respecto a 1992. Esto evidencia que en El Salvador es muy posible que se este dando una política espuria de competitividad, a través de la contención de salarios. Esta política consistiría en contener los salarios nominales medios, de manera que su crecimiento sea menor que el incremento de los precios, y por lo tanto caigan los salarios reales y por lo tanto el costo salarial y el poder adquisitivo de los trabajadores. Al ajustarse los salarios por detrás del ritmo inflacionario, se estaría buscando, ya sea mejorar la competitividad, o enfrentar la creciente competencia de productos importados, o enfrentar a competidores en terceros mercados.

Esta mejora de El Salvador a través de la reducción de los salarios reales seguramente puede atenuar en el corto plazo parte de los estragos del actual auge chino en la industria manufacturera, especialmente en el sector de la confección. Sin embargo, es una vía nociva en el largo plazo para hacerle frente a la competencia internacional.

c) CLU y cuota de mercado

A partir de lo visto anteriormente, se hace necesario hacer una comparación de los CLU relativos con respecto a la evolución de la cuota de mercado de China y El Salvador de las importaciones de confección de Estados Unidos.

$\mathrm{Al}$ analizar la tendencia entre la evolución de los CLU relativos con salarios en dólares y la cuota de mercado de China relativa a El Salvador entre 1992-2003, se observa que la competitividad de El Salvador con respecto a China desmejora. Este hecho coincide en general con el acelerado crecirniento de las exportaciones de confección chinas hacia Estados Unidos, traduciéndose en mayores ganancias de cuota de mercado de esta nación. Ejemplo de lo anterior, es que la tendencia más marcada se dio entre los años 2002 y 2003 después del ingreso de China a la OMC, cuando la ganancia de cuota de mercado de China se incrementó considerablemente de 10.04 a 21.29 . 
La relación que existe entre la evolución de los CLU relativos y las ganancias de mercado de China relativo a El Salvador se logra visualizar expresando las ganancias de mercado de China como la diferencia absoluta de las exportaciones brutas de confección de China y las exportaciones netas de confección de El Salvador hacia Estados Unidos, y los CLU relativos son los de salarias en dólares.

Se observó que en el año 1997, fue el único año en que las exportaciones netas de confección de El Salvador hacia Estados Unidos superaron a las exportaciones brutas de confección de China. Después de 1997 ya se empezaba a ver que la competitividad de El Salvador desmejoraba en relación a China, ya que a partir de 1998 las exportaciones de China de confección comenzaron a superar a las de El Salvador, ganando así cuota de mercado. Es a partir del año 2001, cuando los CLU relativos registraron su mayor decrecimiento haciendo a El Salvador cada vez menos competitivo en relación a China. Prueba de ello es que China superó en un mayor volumen a las exportaciones de confección de El Salvador.

Una manera de ver los impactos iniciales de que tendrá la maquila es a través del Índice de Volumen de la Actividad Económica (IVAE). Este indicador, intenta medir los volúmenes de la actividad económica y busca ser un aproximado de los volúmenes de producción sectoriales. Con respecto a la evolución que ha tenido el IVAE de la maquila para el período entre enero de 1990 y marzo de 2005, se constató que entre los años 1990 y 1997 se registraron los más altos crecimientos del IVAE siendo estos aproximadamente de $70 \%$ en los años 1992 y 1994. Sin embargo, la caída más drástica que refleja el IVAE se dio entre los años 1995 y1997 ya que de crecer en un $50 \%$ en 1995 pasó únicamente a crecer en $10 \%$ en 1997. Durante el año 2003, hubo una leve recuperación. Sin embargo, para mediados del año 2004 hasta los primeros meses de 2005, el IVAE tuvo su peor caída durante el período, ya que ha registrado tasas de crecimiento negativas siendo la más baja de $-20 \%$ en marzo de 2005. Este grave decremento del IVAE de maquila se le puede atribuir al fin del ATV ya que a partir de ese momento China invade el comercio mundial con sus productos de confección lo que ha hecho que El Salvador se enfrente a una mayor competencia, que incluso le ha hecho disminuir su volumen de actividad económica en este rubro, evidenciando así, que uno de los efectos iniciales de la entrada de China a la OMC y del incremento de su cuota de las importaciones de confección de Estados Unidos, sea la caída de los volúmenes de producción y de la dinámica general de la maquila. 
Otra forma de ver los impactos iniciales es a través del empleo, de las empresas y de la inversión que ha tenido la maquila de confección. La maquila ha sido considerada una actividad generadora de empleos, que sin embargo ha experimentado altibajos. Según registros del ISSS, entre 2000 y 2001 , el empleo en la maquila disminuyó en $3.33 \%$. Habría que considerar que una posible explicación de esa reducción en los puestos de trabajo y del pobre desempeño de las tasas de crecimiento de éstos podría deberse al cierre de algunas empresas, motivado tanto por la disminución de los contratos de confección o por lo fuga de los mismos hacia el país asiático, ya que la industria trabaja principalmente subcontratada por empresas de ropa extranjera.

Las informaciones periodísticas destacan que en el último quinquenio, 138 empresas $^{37}$ de textiles y de confección se ubicaron en el país. Sin embargo, hasta el mes de mayo de 2005 se tiene contabilizado el cierre de 12 maquilas de confección, dejando desempleados alrededor de 4,500 trabajadores. ${ }^{38}$ La falta de materia prima para continuar las operaciones $y$ la espera de contratos de trabajo son los motivos aducidos en estos cierres. A pesar de las cifras anteriores que indican alguna reducción de empleo y empresas, la inversión extranjera no se ha visto seriamente afectada todavía, ya que la participación de la inversión de la maquila en la inversión extranjera total ha tenido un leve decrecimiento. Por ejemplo entre los años 2002 y 2003, cuando ya se contaba con la participación de China en la $\mathrm{OMC}$, se registró una disminución de la participación de la maquila en la inversión extranjera de únicamente 0.37 puntos porcentuales. Otros datos periodísticos dan indicios que estas leves reducciones de la IED se pueden deber a que las autoridades gubernamentales desde junio de 2004 han promovido el establecimiento o expansión de 24 empresas extranjeras, lo que podría contrarrestar el cierre de otras empresas que hayan ocurrido, y por ende a ocultar la problemática. Según datos periodísticos los nuevos negocios han invertido $\$ 63$ millones, han generado 4,000 empleos en el segundo semestre de 2004, y 2,000 en el primer trimestre de 2005. Según las cifras del Banco Central de Reserva, durante el primer trimestre del año todas las empresas de capital extranjero en el país han invertido $\$ 3,138$ millones. ${ }^{39}$

El salario real es considerado un indicador de las condiciones de vida de la población asalariada, por lo que se hace necesario hacer una breve reflexión sobre el posible efecto que ha tenido para los salarios reales en El Salvador, el ingreso de China a la OMC. 
La disminución más drástica que han sufrido las remuneraciones del sector ha sido entre el 2000 y 2001, que precisamente coincide con la entrada de China a la OMC. A partir de ese año, los salarios reales se han mantenido bajos y no han podido recuperar los niveles que tenían a principios de la década de los noventa.

El sector confección, al ser parte importante de la manufactura, con mucha seguridad puede estar observando también una tendencia a caer de sus salarios reales, sobre todo ante la percepción de los últimos años por parte de los empresarios de la pérdida de competitividad y de cuotas del mercado frente a China. En ese sentido un efecto indirecto del auge exportador chino podría ser la reducción aun mayor de las remuneraciones o presiones para reducirlas, en el sector de la maquila de confección salvadoreña.

Hay dos datos que dan evidencias en el sentido de un desmejoramiento de las remuneraciones en la maquila: a) el primero es que entre el año de 1999 y 2005 únicamente ha habido un incremento del salario mínimo, ${ }^{40}$ que en el caso de la maquila es un dato de referencia importante sobre las remuneraciones pagadas efectivamente en el sector; b) En segundo lugar, en este último ajuste salarial, se creó un salario mínimo que rige sólo para la maquila, el cuál se incrementó en un $5 \%$ respecto al que regía anteriormente para todo el sector industrial, mientras que el de la industria no maquiladora lo hizo en $7.5 \%$, y el del sector de comercio y servicios $10 \%$.

Los datos anteriores de la manufactura y maquila muestran indicios sobre la existencia de presiones para las reducciones salariales reales $\mathrm{y} / \mathrm{o}$ nominales (medios y mínimos) en la maquila de confección, lo cual, puede ser debido al efecto de retroalimentación que ha causado el auge de la industria china, la poca capacidad de las empresas nacionales de incrementar su competitividad y la pérdida de dinamismo de la maquila salvadoreña. Hay que considerar que el cierre de maquilas que se ha dado o podría estarse dando hasta la fecha, presionará a su vez para que los salarios reales o medios continúen disminuyendo, en la medida que ‘nás personas se encuentren sin empleo. La continuación del auge chino puede agravar esta tendencia, y con seguridad los empresarios presionarán por una mayor reducción de las remuneraciones medias, mínimas y/o reales. La creación de un salario mínimo para la maquila, menor que el resto del sector industrial, es una evidencia fuerte en ese sentido. 
Como ya se ha desarrollado, el hecho de comprimir los salarios nominales y/o reales bien puede ser un camino para reducir los CLU. Sin embargo, se constituye en un elemento de corto plazo para adquirir competencia. Esto es así, porque dicha estrategia de reducción de salarios tendrá un límite social en el país, y por lo tanto no se podrá aplicar ilimitadamente ya que la población necesita de los medios de vida necesarios para reproducirse y subsistir.

El Salvador ha disminuido su competitividad en relación a China, en general, durante el período 1992-2003, y además dado la pobre dinámica mostrada por su productividad, parecen indicar que el panorama para el sector maquilero salvadoreño no es favorable.

Se ha evidenciado que en los primeros tres años de la entrada de China a la OMC, la maquila de confección se ha visto considerablemente afectada mostrando tasas negativas de crecimiento en sus exportaciones, de su producción y de su cuota de las importaciones norteamericanas. A largo plazo, la situación puede empeorar aun más con el fin de las cuotas textiles debido a la expiración del Acuerdo de Textiles y Vestido (ATV) de la OMC en 2005.

Los efectos que tendría para el país que China siga aumentando la cuota que controla en el mercado de confección de Estados Unidos se verán reflejados en diferentes ámbitos económicos del país. El efecto más importante sería sobre el déficit de la balanza comercial. Una reducción drástica de la maquila, dado que es una actividad exportadora neta, se vería reflejado en un incremento del déficit comercial. Una merma considerable de la actividad podría significar un incremento al menos en más del $10 \%$ del déficit comercial.

El empleo es la segunda variable que podría ser la más afectada. El empleo de la maquila representa el $20.05 \%$ del total de ocupados en la industria manufacturera para el año 2003. Por lo tanto, con la continuación del auge chino y el posible cierre de más maquilas podría generarse una reducción considerable del empleo en el país.

Por otra parte, el crecimiento del sector manufacturero se podría ver deteriorado. Entre los años 2001 y 2002 la maquila ha representado entre el $10.60 \%$ a $10.05 \%$ del valor agregado de la manufactura. En caso de verse mermada la actividad maquiladora, ello podría afectar el crecimiento de la manufactura principalmente, y del PIB en general. 
Finalmente, en lo que se refiere a la participación del consumo intermedio de la maquila en la industria manufacturera, este ha aumentado, pero no para representar una cifra significativa. En los últimos años esta actividad se ha mantenido alrededor del $3 \%$ del consumo intermedio de la manufactura. Al ser esta participación poco relevante si la maquila de confección sigue con la misma tendencia decreciente, otras industrias locales podrían experimentar alguna reducción en su demanda.

\section{Conclusiones}

- Las actividades de la confección de China y la maquila de confección de El Salvador mostraron un considerable crecimiento durante los noventa. El auge de esta industria en El Salvador se dio en el primer quinquenio, mientras que en China fue a finales de la década. En ese período, las industrias de ambos países se consolidaron como sectores exportadores netos y mostraron una creciente importancia económica.

- China se ha presentado como un fuerte competidor para El Salvador en el sector de confección de ropa, ya que ambos países exportan productos similares como: pantalones, camisas, blusas, ropa interior, tela en tejido de punto y otros.

- En lo que respecta a las exportaciones chinas de confección, se evidenció que esta nación ha ganado aceleradamente una mayor cuota de mercado en Estados Unidos, desplazando así a otros competidores, como El Salvador, en los últimos años.

- China se podría considerar como el país que posee "los capitales reguladores" en el sector de confección de ropa, y muy posiblemente en la cadena HTC en general. Por lo tanto, es su industria la que regula los precios sectoriales a nivel mundial.

- Se observó que China no depende por completo de Estados Unidos, como El Salvador, debido a que tiene mayor diversificación de mercados, exportando productos de la cadena Hilo-Textil y Confección con procesos productivos de paquete completo.

- Se concluye a través de los CLU, que El Salvador ha optado fundamentalmente por contener los salarios reales, lo cual es una vía espuria de ganar algún grado de competitividad. A diferencia de China que ha optado incrementar su competitividad a través de inversión en avances tecnológicos, lo que le ha permitido incrementar en gran medida su productividad, al mismo tiempo que incrementa sus salarios reales. 
- Otra manera que China tiene de ganar competitividad, es a través del manejo de su política cambiaria, ya que es una forma de abaratar sus exportaciones. El Salvador no posee este instrumento debido a que su tipo de cambio se mantiene fijo desde la dolarización.

- En los últimos años, China ha incrementado su competitividad lo que la ha llevado a tener una mayor cuota del mercado estadounidense por el uso de procesos de producción de alta tecnología y por la política cambiaria. Por el contrario, la cuota de mercado de El Salvador hacia Estados Unidos se ha visto reducida, lo que hace vulnerable a este país frente a la competencia generada por el gigante asiático.

- Se verificó que el dinamismo de la maquila ha disminuido acentuándose aun más desde la entrada de China a la OMC. Esto se reflejó en los últimos años en una disminución en la producción de la maquila, hecho que se pudo evidenciar con la evolución que ha tenido el IVAE a lo largo del período estudiado. Asimismo, las exportaciones netas de confección de El Salvador hacia Estados Unidos llegaron a registrar tasas de crecimiento negativas.

- Se evidenció que el empleo y las empresas nacionales dedicadas a este rubro también han sido afectadas, ya que en los primeros meses de 2005 varias de estas han cerrado operaciones dejando así a miles de trabajadores sin empleo.

- Se encontró que la maquila en los últimos años ha disminuido su importancia respecto del déficit comercial, por lo que de continuar esta tendencia el país se vería en la necesidad de reducir las importaciones no maquileras, así como de incurrir en un endeudamiento externo mayor para lograr cubrir dicho déficit.

- En caso que la actividad maquiladora continúe disminuyendo, no necesariamente podría afectar el crecimiento del PIB en general. En cambio, la industria manufacturera sí se vería afectada con la reducción de la maquila, ya que es parte fundamental de la industria manufacturera.

- En el caso del empleo, si se continúa experimentando el cierre de maquilas, esto llevaría a que se aumente la oferta laboral y a que se continúen deprimiendo los salarios, lo que podría agravar, aun más, el malestar social actual.

Ante los nuevos desafíos que se plantean es necesario que las empresas mejoren la capacidad productiva de su fuerza laboral, actualicen sus 
tecnologías y mejoren sus procedimientos, cambiando sus estrategias de trabajo (como paquete completo) y respondan así a las exigencias de los mercados internacionales.

\section{NOTAS}

1 Los contingentes de importación constituyen cuotas que establecen algunos países a cierto tipo de industrias o productos provenientes de ciertas naciones. A las cantidades que están dentro de los contingentes se les aplican generalmente aranceles inferiores a los vigentes.

2 Organización Mundial del Comercio http://www.wto.org/spanish/tratop_s/texti_s/ texti_s.htm

3 OMC. “Entender la OMC”. $3^{2}$ edición, Septiembre 2003. http:// www.wto.org

1 Ibíd.

s Góchez Sevilla, Roberto; García Dueñas, Gilberto. "La actividad maquiladora en El Salvador, dinámica y evolución en la última década". Marzo de 2002.

- Sistema de Información sobre Comercio Exterior. http://www.sice.oas.org/ctyindex/ wto/svS111e_s.asp\#3)\%20Industria\%20manufacturera

, Banco Central de Reserva. http://www.bcr.gob.sv

a BCR, "Informe de la situación económica de El Salvador, III trimestre de 2004". http://www.ber.gob.sv

9 Microsoft Corporation 1993-2003. "Encarta 2004"

10 Meléndez Arriaza, Jorge. “Código Rojo". $1^{2}$ Edición Septiembre 2004. p. 19

" Estas reformas sin embargo no se han visto acompañadas hasta la fecha en una apertura política.

12 Aquino, Rodríguez Carlos “El desarrollo económico de la República Popular China y su impacto en el Perú y Latinoamérica" http://geocities.com/Eureka/plaza/1406/ artc/impactP_deschina.html.

13 Aquino, Rodríguez Carlos “El desarrollo económico de la República Popular China y su impacto en el Perú y Latinoamérica" http://geocities.com/Eureka/plaza/1406/ arte/impactp_deschina.html.

14 OMC, "concluyen con éxito en la OMC las negociaciones para la adhesión de China" (17 de septiembre de 2001). http://www.wto.org/spanish/news_s/pres01_s/ pr243_s.htm

is El Diario de Hoy. "Los chinos criticaron el bloqueo textilero". Lunes 13 de junio de 2005.

16 La Prensa Gráfica. "China dará licencia a textileros". Miércoles 22 de junio de 2005.

17 El Diario de Hoy. "Medida contra China protege a la maquila". Viernes 27 de mayo de 2005 
18 Prensa Libre, Guatemala. "China, lista para reforma cambiaria". Viernes 13 de mayo de 2005.

19 Domínguez, Nadima Simón. “Competencia de las prendas de vestir mexicanas en el mercado de Estados Unidos". http://www.ejournal.unam.mx

20 Este régimen denominado 807 , que posteriormente se convirtió en 9802 , consiste en que los impuestos deimportación se pagan únicamente sobre el valor agregado en el extranjero y no sobre los componentes estadounidenses que se ocupan para el ensamble.

${ }^{21}$ Guertero Jiménez, Diego. "Competitividad: Teoría y Política”, 1995.

22 Relación de costos dentro de un mismo sector entre países.

23 Maldonado, Engelberto. "Maquila de conlección, sin capacitación no tiene futuro" Diario Co Latino. Lunes 9 de mayo de 2005, p. 4.

24 Depósito para Perfeccionamiento Activo o Recinto Fiscal: áreas que tienen un tratamiento tributario similar a las zonas francas, pero no se encuentran en un área específica, sino que se pueden ubicar en cualquier lugar.

25 Consejo Monetario Centroamericano. "Efectos de la maquila en el sector real y en la balanza de pagos de El Salvador". Documento de Investigación No. 1

26 Hay que tomar en cuenta que entre 1992-1995 se realizaron seis ajustes al salario mínimo, mientras que a partir de 1999 a la fecha sólo se ha realizado uno.

27 Urquilla, Alicia; Pichinte, William; Rodríguez, Claudia. Análisis de Competitividad Industria de la Confección de El Salvador. Subdirección Inteligencia Competitiva Dirección Desarrollo Competitivo Empresarial. Ministerio de Economía. Septiembre 2004.

28 Urquilla, Alicia; Pichinte, William; Rodríguez, Claudia. Análisis de Competitividad Industria de la Confección de El Salvador. Subdirección Inteligencia Competitiva Dirección Desarrollo Competitivo Empresarial. Ministerio de Economía. Septiembre 2004.

29 Góchez Sevilla, Roberto y García Dueñas, Gilberto. "La Actividad Maquiladora en El Salvador, dinámica y evolución en la última década". Marzo de 2002 Federación Internacional de Trabajadores Textiles, Vestuario y Cuero

so Lora, Eduardo. “¿Debe América Latina temerle a la China?”. Banco Interamericano de Desartollo. Mayo 2005. http://www.iadb.org/res/publications/pubfiles/pubWP. 536.pdf

31 Riera Andrés, José Luís. "El tipo de cambio: cun factor más para la competitividad internacional de China?” Boletín Económico de ICE \# 2776 del 1 al 7 de septiembre 2003. http://www.revistasice.com/estudios/documen/bice/2776/BICE27760204.pdf

32 Es de aclarar que las exportaciones de China son brutas debido a que esta nación posee paquete completo, por lo que estas son más relevantes que las exportaciones netas para el análisis.

33 Se toman las exportaciones brutas ya que estas son más representativas que las exportaciones netas debido a que China posee paquete completo 
34 Llorca, Verónica. "El Sector de Tejidos e Hilados en China" Oficina Económica y Comercial España en Shangai Febrero 2004 http://www.icex.es/staticFiles/ 2004_NS_Hilados\%20y\%20Tejidos_6490_.pdf\#search='incentivos

\%20en\%20el\%20sector\%20de\%20confecci\%C3\%B3n\%20de\%20China

3s Guerrero Jiménez, Diego. "Competitividad: teoría y política",1995.

36 Se esta asumiendo que la evolución global de la competitividad manufacturera en China y El Salvador sea un indicador de, o coincida con, la evolución de la misma en la industria de la confección de China y la maquila de confección salvadoreña.

37 El Diario de Hoy. "Llega nueva inversión en el sector textil". Miércoles 6 de julio de 2005.

38 El Diario de Hoy “Efecto China cerró 12 maquilas”. 31 de mayo de 2005, p. 46

39 El Diario de Hoy. "Llega nueva inversión en el sector textil". Miércoles 6 de julio de 2005.

10 Ministerio de Trabajo y Previsión Social. “Salarios Mínimos ${ }^{D}$ http://www.mtps.gob.sv 